ISSN:2528-9527

E-ISSN : 2528-9535

YIl Year: 7

Cilt Volume:7

Sayı Issue : 12

Uluslararası Toplum Araştırmaları Dergisi

International Journal of Society Researches

Haziran June 2017

Makalenin Gelis Tarihi Received Date: 06/06/2017

Makalenin Kabul Tarihi Accepted Date: 12/06/2017

\title{
Kırda Siyasal Davranış: Çukurova Örneği
}

\author{
"Vahit Çalıșır \\ * Dr. Elektrik Üretim A.Ş. Ankara/Türkiye \\ E-Posta: vahitcalisir@gmail.comＯRCID: 0000-0001-6575-8988
}

Öz

Siyasal Davranış, bireylerin içinde bulundukları siyasal sistem içerisinde değişik etmenlere bağhl olarak sergiledikleri siyasa ile alakalı tüm davranışları işaret etmektedir. İnsanların çevreden etkilenmemeleri mümkün değildir. Bu nedenle her siyasal davranışın altında sosyal yaşam ve sosyal etkileşimler yer almaktadır. Bireylerin, aile ile başlayan sosyal sermaye gelişimlerinin daha sonra mahalle, okul, iş ve sosyal yaşamlarının etkisi ile genişlediği ve siyasal davranış üzerinde etki düzeylerinin farklılaştığı bir gerçektir. İnternetin gelişimi ile birlikte artan sosyal medya gücünün kitlesel medya araçlarına eklenmesi ile birlikte son derece farklı bilgi edinim kaynakları ortaya çımıştır. Tüm bunlar, bireylerin ve bireylerin oluşturduğu toplulukların siyasal kültür yapısında ciddi etkiler meydana getirmiştir. Bilgiye erişim yöntemlerindeki yenilikler, sezgisel değerlendirmenin ötesine geçerek bilgiye dayalı bir değerlendirme yolu ile siyasal davranışın şekillenmesine neden olmuştur. Günümüzde kent merkezine yoğunlaşmış nüfusun siyasal davranışını incelemek hususunda araştırmacılar oldukça gönüllü iken kırsalda bu davranışın incelenmesi ihmal edilir hale gelmiştir. Sosyal sermayenin kırsalda gelişimi, bilgiye erişim kaynaklarının çeşitlenmesi, kitle iletişim araçlarının çeşitliliği, siyasal kültür ve bilgi değerlendirme yapıların da değiştirmektedir. Bu çalışmanın ana amacı da kırsalda siyasal davranışı ve kültürü etkileyen faktörleri ortaya koyabilmektir

Anahtar Kelimeler: Siyasal Davranış, Siyasal Kültür, Siyasal Bilgi, Siyasal Katılım, Siyasal Tercih 
ISSN:2528-9527

E-ISSN : 2528-9535

YIl Year: 7

Cilt Volume:7

Sayı Issue : 12

Uluslararası Toplum Araştırmaları Dergisi

International Journal of Society Researches

Haziran June 2017

Makalenin Geliş Tarihi Received Date: 06/06/2017

Makalenin Kabul Tarihi Accepted Date: 12/06/2017

\title{
Political Behaviour in Rural: Çukurova Sample
}

\begin{abstract}
Political Behavior refers to all attitudes act by individuals related to politics depending on the various factors within the political system that they live in. It is not possible not to be effected from environment for human beings. Therefore, there are social life and social interactions beneath all political behaviors. It is a fact that social capital development of the individuals started from the family expands through effects of the school, occupation and social life and differentiates the effect levels on political attitudes. Addition of social media power to mass media means in line with the developments in internet caused extremely different sources of gathering information to be occurred. All of these caused serious effects on the political culture structures of the individuals and the communities composed by the individuals. Innovations on methods of access to information lead to shaping the political attitudes passing beyond intuitive evaluation of the information as knowledge-based information analysis. Contemporarily, while social researchers are very keen to investigate the political behaviors of the population condensed in city centers, the investigation of this behavior in rural regions became neglected. The Development of Social Capital in Rural Areas, Diversification of Access to Information Tools, Diversification of Mass Media Means are all changing the structures of political culture and analyzing information. The main objective of this study is to put the factors that are effecting political behavior and culture in rural areas.
\end{abstract}

Key Words: Political Behavior, Political Culture, Political Knowledge, Political Participation, Political Preferences 


\section{Giriş}

Tek bir tanımı olmamakla birlikte ilk olarak dar anlamda siyasal davranış, siyasal sistem içinde vatandaşların doğrudan ya da dolaylı olarak yöneticilerin seçimini ve kararlarını etkilemeyi amaç edinen eylemlerdeki görüşleridir (Çam, 1987: 283). Bu tanıma göre siyasal davranışın yegâne amacı seçimlerde kimin devleti yöneteceğine karar vermek ve bu yöneticilerin alacağı kararlarda etkili olmaktır.

Siyasal Davranışın tanımına ilişkin bir başka açısı da siyasal otorite ile olan bağlantısına yöneliktir. Buna göre siyasal davranış, bir toplumun üyesi ile o toplumdaki siyasal otorite arasındaki bir bağdır (Kalaycıŏlu, 1983: 10). Bireyin otonom karar ve tercihlerinin siyasal otorite üzerindeki etkisinden oluşan bir ilişkidir (Kalaycıoğlu, 1983: 10). Bu tanıma göre otoritenin kararlarına etki etme özelliği ön plana çıkarılmış ancak otorite olarak kimin tercih edileceği konusuna vurgu yapılmamıştır.

Siyasal açıdan seçmen davranışlarını açıklamaya yönelik ana yaklaşımlar sosyolojik yaklaşım, sosyo-psikolojik yaklaşım ve ekonomik yaklaşım olarak üç adettir.

\section{Sosyolojik Yaklaşım}

Genel itibari ile sosyolojik yaklaşım (Columbia ekolü olarak bilinir) seçmenlerin parti tercihleri sanki dini bir aidiyet ve vazgeçilmez alışkanlıklar olarak tanımlanır ve seçmenlerin her bir seçimde kullandığı oy da bu değişmez kimliğin teyidinden başka bir şey değildir (Norris, 1998: 113). Burada oluşturulan temel bireyin kimliğini de ortaya koymaktadır.

Modelin temeli, ferdin tutum ve tercihlerinin ilişkide olduğu insanlardan etkileneceği (Özcan 1998: 195) varsayımına dayanmaktadır. Seçimlerde kullanılan oy da aslında bireylerin ait olduğu sosyal kimliklerin siyasal tercihlere yansımasından ibarettir düşüncesi ile hareket eder (Akgün, 2007: 27). Bu yaklaşıma göre seçmen davranışının temelde toplumdaki sosyal bölünmüşlük tarafından belirlendiğini iddia eder (Akgün 2000: 77). Sosyolojik yaklaşım; seçmenlerin daha çok din, sosyo-ekonomik statü, yaşadığ1 yer, mensubu olduğu grup vb. faktörleri ön plana çıartan yaklaşımdır. Yani bu yaklaşımın temel konusu seçmenden ziyade, 
seçmenin mensubu olduğu gruplar ve partilerdir (Kalander, 2005: 40). Eğer belirli bir yerde ki insanların siyasal tercihlerin anlaşılması isteniyorsa o insanların nerede yaşadıklarını, çevrelerinde ne tür durumların şekillendiğini ve çevrenin (fiziki, sosyal, ekonomik... vb) onları nasıl etkilediğinin bilinmesi gerekir.

Bu bakış açısı ile zaman ve mekândan soyut bir genellemenin doğru olmadığı görülmektedir (Carmins ve Huckfeldt, 1992: 117-134). Özetle, bireysel amaç ve çevresel durum etkileşimini, siyasal sosyoloji geleneğinin ortaya çıktığı erken dönemlerde, bir tema olarak bireysel vatandaşları çevreleyen bağlam ve ağlara bağlı şekilde oluşan siyasal sonuçlar olarak ele alındığını görüyoruz (Carmins ve Huckfeldt, 1992: 117-134). Bağlam (Context) sosyal bağlamı ve A $\breve{g}$ (Network) de bireyin sosyal çevresini ifade etmektedir.

Sosyal bağlam ve ağları işaret eden modern seçim çalışmalarının literatürde başlangıcını yapan ilk çalışmalar Warren Miller (1956) ve Robert Putnam (1966)'ın çalışmalarıdır (Carmins ve Huckfeldt, 1992: 117-134). Bu çalışmalar aynı zamanda sosyal sermaye kavramını vurgulamaları nedeniyle literatürde sosyal sermaye açısından önemli yer tutmaktadırlar.

\section{Sosyo-Psikolojik Yaklaşım}

Bu model ilk defa Michigan Üniversitesi'nden Campbell, Converse, Miller ve Stokes tarafından geliştirilmiş ve yazarlar, seçmen tercihi araştırmalarına yeni bir boyut kazandırmıştır. Partiyle özdeşleşme modeli; 1948, 1952 ve 1956 Başkanlık Seçimleri arasında görüşmelerin verileri doğrultusunda ortaya konulmuştur (Campbell ve ark. 1976: 10). Model sadece sosyal temeli ele almaz aynı zamanda sempatik kanalları da göz önünde bulundurur.

Modelin özü, seçmenin bir partiye duyduğu sevgi ve bağlllı̆̆ ifade etmektedir. Bu bağlılık, bir taraftarın futbol takımı tutması gibi de değerlendirilmektedir. Bireyin partisiyle özdeşleşmesi için herhangi hukuki bir bağının bulunması da şart değildir (Özkan: 2007: 1-172). Birey, bilinçaltı ve içgüdüsel baskılar altında tercihini yapar. Bu psikolojik dürtüler ise oy vermede rasyonellik ilkesinin işlemesini engeller (Gülmen, 1979: 41). Seçmenlerin küçük yaşlarda ailelerinin ve çevrelerinin etkisi altında gerçekleşen siyasal sosyalleşme sürecinde kazandıkları siyasal tutumlar 
ve ideolojik yönelimlerin ileriki yaşlarda onların parti tercihi üzerinde son derece etkili olduğu (Akgün, 2007: 29) ve kişilerin herhangi bir partiye karşı psikolojik bağlılık duyduğunu iddia eder (Kalender, 2005: 46). Sosyo-psikolojik yaklaşım, "Parti Kimliği" kavramını literatüre kazandıran yaklaşımdır. Buna göre bireyler küçük yaşlardan itibaren yakın çevresinden etkilenerek belli bir siyasal düşünceye ilgi duymaya başlar ve bu psikolojik bağlllık zamanla güçlenerek devam eder.

\section{Ekonomik Yaklaşım (Rasyonel Tercih)}

Anthony Downs'in "An Economic Theory of Democracy" isimli çalışmasında ortaya koyduğu parti rekabeti ve oy kullanma kavramından hareketle "rasyonel yaklaşım" modeli geliştirilmiştir (Scarbrough: 1984:3). Rasyonel yaklaşım içinde aydınlanma fikrinin temel yaklaşımlarını da barındırmıştır.

Rasyonel tercih ya da diğer bir ifade ile ekonomik tercih yaklaşımı, seçmenin kendi çıkarları doğrultusunda en iyi hizmeti verebilecek bir aday ve partiyi değerlendirerek buna göre oy verme eğiliminde olmasıdır. $\mathrm{Bu}$ yaklaşımda seçmenin amaç ve istekleri ön planda tutulmaktadır (Kalender, 2005: 50-51). Rasyonel tercih yaklaşımı seçmeni önemli bir öge haline getirerek seçim sürecini tanımlamaya çalışmıştır.

Rasyonel tercih model genel olarak toplumsal grupların davranışlarından ziyade bireysel davranışa odaklanır. Sosyolojik ve sosyo-psikolojik yaklaşımın aksine bu yaklaşımda oylama, eski alışkanlıklar, parti kimliği gibi bağllık ve sadakat olarak değil, bireysel bir çıkara dayalı bir hedefe ulaşmak için kullanılan temel bir araçtır. Dolayısıyla bu model oy vermeyi, hem iktidardaki partinin geçmişe dönük yorumu ve bu partinin gösterdiği performansın vatandaşların tercihlerini nasıl etkilediğinin bir göstergesi hem de, seçmeni mevcut siyasa seçenekleri arasından bir tercih yapan tüketici olarak görmektedir (Heywood, 2007: 352). Ekonomik yaklaşım son dönemlerde ki ismi ile "Rasyonel Seçim - Rasyonel Çıkarcılık" olarak da bilinen ekonomik oy verme "economic voting" yaklaşımıdır (Akgün, 2007: 29). Ekonomi biliminde kullanılan "Rasyonel Tercih" yasasına paralel şekilde tesis edilmiş olan yaklaşıma göre seçmen ekonomik çıkarları ile örtüşen rasyonel tercihlerde bulunacaktır (Bennet 
ve Salisbury, 1987: 1-30). Rasyonel tercihler amaca ulaşmada önemli araçlar olarak ortaya çıkmaktadır.

\section{Yöntem}

\section{Araştırma Sahası}

Çukurova (Eski adıyla Kilikya) Mersin, Adana, Osmaniye ve Hatay'ı içine alan coğrafya 'ya verilen isimdir. Araştırmada Mersin Adana ve Osmaniye illeri çalışılmıştır.

Hatay bölgesi kendine has demografisi ve kültürel yapısı ile diğer 3 ilden farklı bir yapıya sahiptir. Hatay'ın siyasal davranışlarını temellendiren unsurlar diğer illere nispeten daha çeşitlidir. Buna bağlı olarak araştırmanın bütünlüğü nedeniyle araştırmaya dâhil edilmemiştir.

\section{Katılımcilar}

Araştırmada 370 denek (118 Kadın, 252 Erkek) ile görüşülmüştür. Bu deneklerin illere göre dağılımı şu şekildedir.
Adana
142 Denek
Mersin
141 Denek
Osmaniye
87 Denek

\section{Veri Toplama Aracı}

Araştırmada öncelikli veri toplama tekniği olarak anket kullanılmıştır. Anketin içeriği 6 ana başlıkta - Demografi, Siyasal Davranış, Siyasal Bilgiye Erişim ve Siyasal Bilgi Düzeyi, Kitlesel Medya ve Sosyal Sermaye, Siyasal Katılım ve Siyasal Tercihler - toplanmıştır.

\section{Gruplandırılarak Belirlenen Değişkenler}

Araştırmada siyasal davranış yaklaşımı, sosyal sermaye düzeyi, siyasal bilgi düzeyi, siyasal katılım değişkenleri her bir katılımcı için cevap verdikleri sorulara puanlama yapılarak gruplandırılmış ve sayısal aralıklara yerleştirilmiştir. 


\section{Kullanılan İstatistiksel Yöntemler}

Araştırmada betimleyici istatistikler kullanılarak frekans tabloları elde edilmiştir. Ayrıca ortalama, standart sapma, maksimum ve minimum değerler sunulmuştur. Değişkenler arasındaki ilişkileri incelemek için kikare testi uygulanmıştır.

\section{Bulgular}

Tablo 1: Katılımcıların Sergiledikleri Siyasal Davranış Türleri

\begin{tabular}{llllll}
\hline & Frekans & Yüzde & $\begin{array}{l}\text { Geçerli } \\
\text { Yüzde }\end{array}$ & $\begin{array}{l}\text { Kümülatif } \\
\text { Yüzde }\end{array}$ \\
\hline \multirow{6}{*}{ Geçerli } & Sosyolojik & 173 & 46,8 & 54,7 & 54,7 \\
& Sosyo-Psikolojik & 73 & 19,7 & 23,1 & 77,8 \\
& Rasyonel Tercih & 70 & 18,9 & 22,2 & 100,0 \\
Kayıp & Toplam & 316 & 85,4 & 100,0 & \\
Toplam & Belirsiz & 54 & 14,6 & & \\
\hline
\end{tabular}

Araştırmanın temel amacı olan kırda siyasal davranış, araştırma bölgesinde tablo 1 de görüldügü gibi ölçülmüştür. Buna göre Çukurova bölgesinde baskın davranış türü \% 54,7 ile sosyolojik yaklaşımdır. İdeolojik ve Ekonomik yaklaşım oranları birbirlerine oldukça yakındır.

Araştırmada siyasal davranış ile demografik değişkenler arasındaki ilişkiler de incelenmiştir. Çukurova kırsalında, cinsiyet ve eğitim durumunun siyasal davranış ile aralarında anlamlı bir ilişki olmadığı görülmüştür. Ancak, siyasal davranış ile siyasal görüş arasında yapılan ki-kare testine göre hesaplanan değer beklenen değerden büyük $(50,912>0,66)$ ve $\mathrm{p}<0,05$ olduğu görülmüştür ve buna göre siyasal görüşün siyasal davranış arasında anlamlı bir ilişki olduğu tespit edilmiştir.

Araştırmanın ikinci bölümünde katılımcıların sosyal sermaye düzeyleri ele alınmıştır. Sorulan sorulara verilen cevaplara göre katılımcıların sosyal sermaye yapıları 0 ile 10 puan arasında iki puanlık gruplara ayrılarak ele alınmıştır. Buna göre; 
Tablo 2: Katılımcıların Sosyal Sermaye Düzeyleri

\begin{tabular}{lllll}
\hline & Frekans & Yüzde & $\begin{array}{l}\text { Geçerli } \\
\text { Yüzde }\end{array}$ & $\begin{array}{l}\text { Kümülatif } \\
\text { Yüzde }\end{array}$ \\
\hline 0-2 puan arası çok düşük & 30 & 8,1 & 8,1 & 8,1 \\
3-4 puan arası düşük & 49 & 13,2 & 13,2 & 21,4 \\
5-6 puan arası orta düzey & 81 & 21,9 & 21,9 & 43,2 \\
7-8 puan arası iyi düzey & 193 & 52,2 & 52,2 & 95,4 \\
9-10 puan arası çok iyi düzey & 17 & 4,6 & 4,6 & 100,0 \\
Toplam & 370 & 100,0 & 100,0 & \\
\hline \multicolumn{2}{c}{} & Min & \multicolumn{2}{c}{ Maks. } \\
\hline Ortalama & St. Sapma & 0 & \multicolumn{2}{c}{10} \\
6,2568 & 1,97862 & &
\end{tabular}

Çukurova kırsalında, araştırma katılımcılarının \% 21,3'ünün çok düşük sosyal sermaye yapıları olduğu, \% 21,9'unun orta düzey ve $56,8^{\prime}$ inin yüksek sosyal sermaye yapısı olduğu görülmektedir.

Sosyal Sermaye ile cinsiyet, eğitim durumu ve siyasal kimlik değişkenleri arasındaki ilişkilerde incelenmiştir. Cinsiyet ve Sosyal Sermaye arasında yapılan ki-kare testinde hesaplanan değer 83,045, beklenen değer 0,32' den büyük ve $p<0,05$ olarak tespit edilmiş ve bu iki değişken arasında anlamlı bir fark olduğu değerlendirilmiştir.

Ayn şekilde eğitim durumu ve sosyal sermaye arasında yapılan ki-kare testinde hesaplanan değer 80,588 beklenen değer 0,09'dan büyük ve $p<0,05$ olarak elde edilmiştir. Eğitim ile sosyal sermaye arasında anlamlı bir ilişki olduğu açıkça görülmektedir.

Tablo 3: Katılımcılarn Siyasal Bilgi Düzeyleri

\begin{tabular}{lll}
\hline & Frekans & Yüzde $(\%)$ \\
\hline $0-2$ puan arası & 117 & 31,6 \\
$2,1-4$ puan aras1 & 77 & 20,8 \\
$4,1-6$ puan aras1 & 111 & 30,0 \\
$6,1-8$ puan aras1 & 36 & 9,7 \\
$8,1-10$ puan arası & 29 & 7,8 \\
Toplam & 370 & 100,0 \\
\hline
\end{tabular}

\begin{tabular}{llll}
\hline Ortalama & St.Sapma & Min & Maks \\
3,8162 & 2,79521 & 0 & 10 \\
\hline
\end{tabular}


Araştırmada ele alınan bir diğer konu da katılımcıların siyasal bilgi düzeyidir. Araştırmada sorulan siyasal kavramları tanımlama durumuna göre katılımcılara yapılan siyasal bilgi puan gruplamasının sonuçları aşağıdaki gibidir.

Araştırma bölgesinde 4,1 - 6 puan grubunu baraj yapacak olursak bu puanın altında kalan, diğer bir ifade ile siyasal ve ekonomik kavramlar hakkında bilgi düzeyi düşük kesim tüm örneklemin \% 52,4 ünü oluşturmaktadir.

Orta düzeyde bilgi sahibi olan grup ise (4,1 6 puan grubu) \% 30 ve üst seviye bilgiye sahip grup (6,1-8 ve 8,1 - 10 puan grupları) örneklemin $\% 17,5$ 'ini oluşturmaktadır.

Siyasal bilgi ve sosyal sermaye arasında bir ilişki olup olmadığını değerlendirmek için yapılan ki-kare testinde hesaplanan değer 88,910'nun beklenen değer 1,33'den anlamlı derecede büyük olduğu ve $p<0,05$ olduğu görülmüştür.

Tablo 4: Katılımcılarn Siyasal Katılım Düzeyleri

\begin{tabular}{lllll}
\hline & Frekans & Yüzde & Geçerli Yüzde & Kümülatif Yüzde \\
\hline, 00 & 90 & 24,3 & 24,3 & 24,3 \\
1,00 & 60 & 16,2 & 16,2 & 40,5 \\
2,00 & 72 & 19,5 & 19,5 & 60,0 \\
3,00 & 45 & 12,2 & 12,2 & 72,2 \\
4,00 & 29 & 7,8 & 7,8 & 80,0 \\
5,00 & 26 & 7,0 & 7,0 & 87,0 \\
6,00 & 17 & 4,6 & 4,6 & 91,6 \\
7,00 & 11 & 3,0 & 3,0 & 94,6 \\
8,00 & 5 & 1,4 & 1,4 & 95,9 \\
9,00 & 10 & 2,7 & 2,7 & 98,6 \\
10,00 & 5 & 1,4 & 1,4 & 100,0 \\
Toplam & 370 & 100,0 & 100,0 \\
\hline \multicolumn{5}{c}{} \\
Ortalama & Std. SapmaMin. & Maks. \\
2,5514 & 2,46357 & 0,00 & 10.00 \\
\hline
\end{tabular}

Araştırmada son olarak katılımcıların siyasal katılım düzeyleri ele alınmıştır. Sorulara verilen cevaplara göre 1 ile 10 puan arasında bir katılım düzeyi belirlenmiştir. Tablo 4 'te görüldüğü üzere Çukurova kırsalında 0-5 puan arasında düşük katılıma sahip seçmen oranı örnekleme göre \% 87' dir. 
Orta katılım düzeyine sahip seçmen oranı (6-8 puan grubu) \% 9'dur. Aktif katılım olarak ifade edilebilecek düzeyde olanların oranı (9-10 puan grubu) $\% 4,1^{\prime}$ dir.

Siyasal bilgi ile siyasal katılım arasında anlamlı bir ilişki olup olmadığını değerlendirmek amacı ile yapılan ki kare testinde beklenen değer hesaplanan değerden büyük ancak $p$ değerinin $0,05^{\prime}$ den büyük olduğu görülmüştür.

\section{Sonuç}

Araştırma sahası Türkiye' nin Orta ve Doğu Akdeniz olarak bilinen Çukurova bölgesindeki kırsal kesimi kapsamaktadır. Mersin, Adana, Osmaniye ve Hatay illerinden oluşan Çukurova Bölgesinde Mersin, Adana ve Osmaniye' den farklı kültürel ve siyasal bir yapıya sahip olması nedeniyle Hatay ili araştırmaya dâhil edilmemiştir.

Araştırma bölgesinde baskın davranış türü \% 54,7 ile sosyolojik yaklaşım olduğu görülmüştür (bkz Tablo 1). İdeolojik yaklaşım ve rasyonel tercih yaklaşımının oranları ise sırasıyla \% 22 ve \% 23 ile birbirlerine yakındır. Kırsalda seçmenlerin parti tercihlerinin esnekliği oldukça zayıf olarak değerlendirilmektedir. Konjuktürel değişimlere karşı siyasal tercihlerinde anlamlı düzeyde değişiklik yapabilecek grubun rasyonel tercih yaklaşımı sergileyenler olduğu göz önüne alındığında Çukurova Kırsalında bu oran \% 23 civarındadır.

Bulgularda ikinci bölüm olarak ele alınan faktör, kırda siyasal davranış1 etkileyen bir unsur olarak Sosyal Sermayedir. Sosyal sermaye kavramı kısaca insan ilişkileri içerisinde zamanla birikmiş kaynaklardır. Bir toplumda sosyal sermaye, normların, değerlerin ve ağların bütününü işaret eder (Portes, 1998: 1-24). Kırsal topluluklar şehir yaşamında hazırda bulunmayan türde bir sosyal sermaye tesis edebilirler (Gilbert, Karahalios ve Sandvig, 2010: 1367-1388). Yüksek nüfus yoğunluğuna sahip yerleşim yerleri önemli ve güçlü bağlara ait ağların dışında bulunan saf bilgiye ulaşmayı sağlayan zengin sosyal sermaye üretebilirler ancak bağları zayıftır (Jacobs, 1961: 1-12). Bu tanımlara bakıldığında kırdaki sosyal sermaye yapısının toplumsallaşma mekanları (kahvehaneler, komşu ziyaretleri...etc) etrafında şekillenmektedir. Kanaat önderleri, aile ve komşuluk bu sermaye yapısının beşeri etkenlerini teşkil etmektedir. Buna göre değerlendirilerek anket sorularından puanlama yoluyla elde edilen 
sosyal sermaye seviyesi genel ortalama olarak 6,25 puan olarak (max 10 puan) görülmüştür. Kırın kendisine özgü sosyal sermayesi olduğunu hatırda tutarak araştırma bölgesinde sosyal sermaye seviyesinin orta düzey olduğu değerlendirilmektedir.

Siyasal davranışı etkilediği öngörülen bir diğer faktör de siyasal bilgi düzeyidir. Araştırma içerisinde siyasal kavramlara ilişkin bilinç düzeyleri tespit edilmeye çalışılmış ve puanlama ile her bir denek için ayrı bir siyasal bilgi düzeyi tespit edilmiştir. 0 ile 10 puan arasında değerlendirilen deneklerin ortalama bilgi düzeyi 3.82 ile oldukça düşük olduğu görülmüştür (bkz tablo 3).

Son olarak araştırmada katılımcıların siyasal katılım düzeyi tespit edilmeye çalışılmıştır. Deneklerin verdikleri cevaplara istinaden yukarıda ifade edilen diğer değişkenlerde olduğu gibi 0 ile 10 puan arasında bir değer aralığ 1 belirlenmiştir. Buna göre araştırma bölgesinde deneklerin siyasal katılım düzeyleri ortalaması 2.55 puan olarak çok düşük olduğu tespit edilmiştir.

Sonuç olarak Çukurova Kırsalında yapılan araştırmaya katılan deneklerin genel özellikleri şu şekilde ifade edilebilir;

Siyasal tercihlerde farklılık gösterme oranı \% 23 civarındadır. Denekler, çoğunlukla sürekli aynı partiye oy vermektedirler (\% 54) ya da ideoloji olarak (\% 22) benimsedikleri partilerden vazgeçmemektedirler.

Sosyal sermaye yapıları medyanın dışında toplumsallaşma mekânları olarak kahvehane ve aileler arası misafirlikler de gelişmektedirler. Kırsal anlamda iyi sayılabilecek bir sosyal sermaye seviyesine sahiptirler.

Siyasal Bilgi ve Siyasal Katılım olarak araştırmaya katılan denekler oldukça düşük bir ortalamaya sahiptir.

\section{Kaynakça}

Akgün, B. (2002). Türkiye'de Seçmen Davranışı, Partiler Sistemi ve Siyasal Güven, Ankara: Nobel Yayın Dağıtım.

Akgün, B. (2007), Türkiye'de Seçmen Davranışı, Partiler ve Siyasal Sistem, Ankara: Nobel Yayınları.

Campbell A ve ark (1976) The American Voter, The University of Chicago Press, Chicago, 10. 
Carmines \& R. Huckfeldt. (1992). "Party Politics in the Wake of the Voting Rights Act," in B. Grofman and C. Davidson, eds. Controversies in Minority Voting. Washington, D.C.: Brookings.

Çam, E., (1987) Siyaset Bilimine Giriş , İstanbul Der. Yayınları, s. 283

Gülmen, Y. (1979). Türk Seçmen Davranışı. İstanbul: İstanbul Üniversitesi Yay.

Heywood, A. (2007). Siyaset. Ankara: Adres Yayınları.

International Studies, Vol:23, Issue:01, p: 5-26.

Bennet, Lance W. ve Barts R. Salisbury (1987) “Rational Choice: The Emerging Paradigm in Election Studies", (Ed. Samuel Long), Research in Micropolitics, V.2: JAI Press Inc., p. 1-30.

Kalaycıŏglu, E. (1983). Karşılaştırmalı Siyasal Katılma Siyasal Eylemin Kökenleri Üzerine Bir İnceleme, İ.Üni. SBF Yayınları, İstanbul.

Kalender, A. (2005). Siyasal İletişim: Seçmenler Ve İkna Stratejileri. Konya: Çizgi Kitabevi.

Norris, P. (1998). The battle for the campaign agenda" in A King, D Denver, I McLean, P Norris, P Norton, D Sanders, P Seyd New Labour Triumphs: Britain at the polls (Cahtham, NJ:Chatham House), pp 113-144.

Özkan, A. (2007) Oy Verme Davranışı ve Siyasal İletişim. Siyasal İletişim Stratejileri, TASAM Yayınları. Syf 1-72.

Scarbrough, E. (1984). Political Ideology and Voting: An exploratory study, Clarendon Press, Oxford.

\section{Kaynakça Bilgisi / Citation Information}

Çalışır, V. (2017). Kırda Siyasal Davranış: Çukurova Örneği , OPUS Uluslararası Toplum Araştırmaları Dergisi, 7(12), 145-156. 